\title{
Novel Outreach Program and Practical Strategies for Patients with Parkinsonism in the COVID-19 Pandemic ${ }^{1}$
}

\author{
Brianna Sennott ${ }^{\mathrm{a}}$, Katheryn $\mathrm{Woo}^{\mathrm{a}}$, Serena Hess ${ }^{\mathrm{b}}$, Daniela Mitchem ${ }^{\mathrm{b}}$, Ellen C. Klostermann ${ }^{\mathrm{b}}$, \\ Erica Myrick ${ }^{\mathrm{b}}$, Sharlet Anderson ${ }^{\mathrm{b}}$, Rodolfo Savica ${ }^{\mathrm{c}}$ and Jori E. Fleisher ${ }^{\mathrm{b}, *}$ \\ ${ }^{a}$ Rush Medical College, Rush University Medical Center, Chicago, IL, USA \\ ${ }^{\mathrm{b}}$ Section of Movement Disorders, Department of Neurological Sciences, Rush University Medical Center, \\ Chicago, IL, USA \\ ${ }^{\mathrm{c}}$ Department of Neurology, Mayo Clinic College of Medicine, Mayo Clinic, Rochester, MN, USA
}

Accepted 14 July 2020

\begin{abstract}
The coronavirus disease 2019 (COVID-19) pandemic has upended daily life and neurologic care for most patients, including those with Parkinson's disease and parkinsonism. Disruptions to routine care, high volumes of patient and caregiver calls, and our patients' risk of infection and complications inspired a proactive COVID-19 outreach program. This program targets patients with advanced Parkinson's disease and related disorders, specifically those who are homebound, receiving or eligible for palliative care, and/or lacking support networks. We describe the program and practical strategies providers can implement to support wellbeing and successful telehealth uptake during this time of social isolation and gradual reopening.
\end{abstract}

Keywords: COVID-19, coronavirus, Parkinson's disease, patient education, outreach, well-being, telemedicine

\section{INTRODUCTION}

The coronavirus disease 2019 (COVID-19) pandemic surpassed ten million cases globally [1], changing typical life and medical care for patients with Parkinson's disease (PD) and related movement disorders $[2,3]$. There are neurologic manifestations of COVID-19 [4, 5] and an evolving understanding of COVID-19 risks associated with PD and subsequent outcomes [6, 7]. PD has been associated with higher risks of complications and hospitaliza-

\footnotetext{
${ }^{1}$ This article received a correction notice (Erratum) with the reference: 10.3233/JPD-219009, available at https://content.ios press.com/articles/journal-of-parkinsons-disease/jpd219009.

${ }^{*}$ Correspondence to: Jori Fleisher, MD, MSCE, Rush University Parkinson's Disease and Movement Disorders Program, 1725 W. Harrison Street, Chicago, IL 60612, USA. Tel.: +1 (312) 563 2900; Fax: +1 (312) 563 2024; E-mail: jori_fleisher@rush.edu; Twitter: @JoriFleisher
}

tion for respiratory illness [8], and higher rates of medical comorbidities $[9,10]$. Early in the pandemic, these factors, care disruptions, and potential virusassociated risks raised significant concern about vulnerable patients within our movement disorders practice, inspiring a proactive COVID-19 outreach program. Our longitudinal work with homebound individuals with advanced PD and parkinsonism [11-13], an already socially-isolated group, informed the program, strategies, and resources recommended.

\section{COVID-19 OUTREACH PROGRAM}

Pre-COVID-19, several authors (SH, DM, ECK, $\mathrm{EM}, \mathrm{JF})$ were following two research cohorts of homebound, advanced PD and atypical parkinsonism patient-caregiver dyads via interdisciplinary home visits. Additionally, we had established an 


\section{Sheltering in Place}

How are they implementing shelter-in-place?

- Minimize who leaves and enters the house

- Wear mask and gloves if leaving

Home Safety

Do the patient and caregiver(s) feel safe at home?

- Falling at home

- Eating, drinking and personal hygiene

- Affording rent, utilities, etc.

\section{Well Being}

How is everyone coping with all the changes in the world?

- Resources for emotional well being and keeping in touch with loved ones

- Resources for home exercise

- Resources for staying occupied and cognitively engaged

- Phone call with therapist for those in need of additional emotional wellbeing support and resources

\section{Prescriptions}

How are medications being obtained?

- Mail order or pharmacy delivery

- Ensure up-to-date and 90-day supply at home

\section{Medical Care}

Telemedicine and avoidance of hospital if possible.

- Prevention - Extreme fall precautions

- Call 911 in case of medical emergency

- If going to hospital, carry cell phone, medication list, copy of insurance card, contact information for family and doctors, advanced directive / DNR / Physician/Medical Orders for Life Sustaining Treatment (POLST/MOLST) paperwork

- Remind about likely visitor restriction and need to have all important information and documents

- Letter on hospitalization during the time of COVID-19 from Parkinson's Foundation

As regions are reopening, these precautions are still important to observe.

Fig. 1. Talking points developed for COVID-19 outreach program involving telephone calls to vulnerable patients.

interdisciplinary neuropalliative clinic for individuals with advanced parkinsonism. In March 2020, we designed the Rush University Parkinson's Disease and Movement Disorders COVID-19 Outreach Program, and received philanthropic support in late April. The program entails a nurse and licensed clinical social worker (LCSW) proactively calling vulnerable, high-risk patients to conduct a targeted needs assessment and provide tailored resources and referrals. LCSWs specialize in treating and preventing mental illness and helping people obtain tangible services. Outreach patients, drawn from the cohorts above, included those who were: homebound per Medicare criteria [14], Hoehn \& Yahr Stage 4-5, receiving or candidates for palliative or hospice care, or with pre-existing high caregiver strain or social isolation according to healthcare professionals' judgment. On average, 27.6 patients meeting these criteria were seen by this team monthly in the six months preCOVID-19 (mean of 12 home visits, 15.6 outpatient visits). Outreach efforts were intended to supplement, not replace, care during the pandemic, and were offered in addition to scheduled, quarterly research home visits and neurologic visits, all transitioned to virtual format. Calls were prioritized for individuals who were not seen recently or scheduled for an upcoming appointment. As this was an urgent clinical and educational response to the pandemic, we present program metrics without individual patientlevel data.
Team members used a note template in the electronic medical record with talking points that were formulated to keep patients informed and prepared for pandemic effects on daily life (Fig. 1). Beyond ensuring access to housing, food, and medications, wellbeing is assessed. Because the population is at high risk for psychological issues and isolation [15-17], the team asks about depression, anxiety, and loneliness. If patients lack emotional support, they are referred to no-cost, brief counseling and resource provision from a neuropsychologist. If additional psychological support is required, the LCSW provides a tailored list of covered providers.

Because parkinsonian patients have higher rates of in-hospital complications [18-20], strategies and safety tips to prevent unnecessary hospitalization are covered. The team addresses advance care planning and provides anticipatory guidance for hospitalization during COVID-19, including a Parkinson's Foundation letter that functions as a surrogate advocate regarding PD medications and contraindications. Additionally, the team provides health literacyfriendly [21] resources to help families navigate difficult conversations (Fig. 2).

Team members discuss lifting of lockdown restrictions and navigation of healthcare appointments, therapy sessions, essential vs. non-essential needs, and social gatherings. Despite re-openings, all benefit from reminders that infection risk continues during this first wave, a second wave may occur, and 


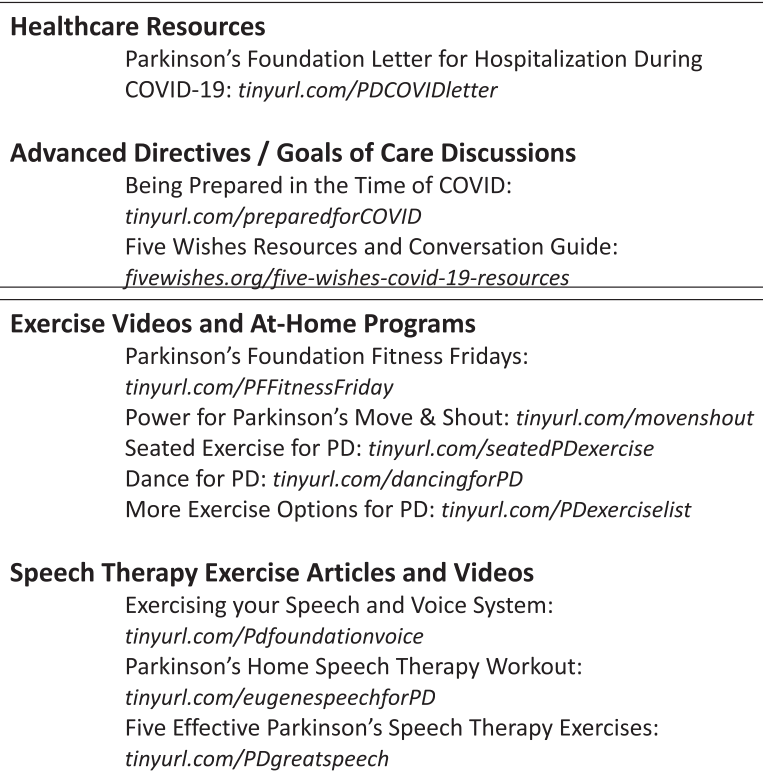

Fig. 2. Collected resources to support patients at home during social isolation due to the COVID-19 pandemic.
Meditation, Relaxation, and Positive Psychology PMD wHolistic: tinyurl.com/PMDwHolistic Happify: happify.com 10\% Happier: tinyurl.com/covidsanityguide Headspace: tinyurl.com/headspacecovid Online Support Group: tinyurl.com/stanfordPDSG

\section{Cognitive Engagement}

Free online access to your local library's digital collection: Libby: overdrive.com/apps/libby

Subscription services for books, audiobooks \& magazines: Scribd: scribd.com Audible: audible.com

Online academic courses: Coursera: coursera.org The Great Courses: thegreatcourses.com/covid19 Virtual tours of famous sites: Yellowstone Park: tinyurl.com/yellowstonevirtual Virtual Treks Worldwide: tinyurl.com/maptreks National Zoo Pandas: tinyurl.com/nationalpandawebcam

Confidential Emotional and Crisis Support

Call Lifeline at 800-273-8255

Call Disaster Distress Helpline at 800-985-5990 Text TalkWithUs to 66746 that high-risk individuals should avoid unnecessary exposures. This includes consistent use of face masks, maintaining social distancing, and rescheduling inperson appointments to telehealth, if appropriate.

In the first two months of the program, 58 calls were attempted, with 45 reaching the patient and/or caregiver. For the 13 unanswered calls, at least two attempts were made. In total, team members spent a mean of 37.0 minutes per completed call. The team identified previously-unaddressed psychosocial stressors, and assisted families with the following: obtaining a primary care physician; hospice service referrals; arranging follow-up care after hospitalization for COVID-19; mental health resources; and medication management. Frequent questions included mask-wearing guidelines, hospital visitor restrictions, safe interactions with non-cohabitating family, and social distancing as lockdowns decline. To date, $93.3 \%$ of caregivers requested and received the "Hospitalization During COVID-19" letter. Two individuals (4.4\%) requested and received neuropsychological counseling, and four individuals $(8.8 \%)$ engaged in discussions of advance directives or code status.

All patients and caregivers voiced appreciation for the proactive approach, particularly those lacking an extended family network. Many noted that these calls made them feel "more safe and supported". Families conveyed positive feedback to our center's other neurologists and staff, who have subsequently adopted these efforts. We conservatively estimate that program components have been disseminated to $15-20 \%$ of the 4400 patients annually seen in the outpatient clinics.

Many organizations have offered COVID-19related educational outreach and support programs. This program is unique because our established relationships and insight into patients' medical and social conditions afford the ability to tailor recommendations, adjust medications, order durable medical equipment, and facilitate continuity of care with other professionals. Identifying vulnerable individuals preCOVID-19 allowed us to efficiently reach those most likely to benefit from proactive outreach, preventive strategies, and anticipatory guidance, and simultaneously narrowed the program's scope, enabling completion.

\section{ADDITIONAL PRACTICAL STRATEGIES FOR SOCIAL ISOLATION AND TELEHEALTH}

Outreach calls and routine care during COVID19 have revealed novel challenges and opportunities, including promoting wellbeing during social isolation and transitioning to telehealth. Providers are primed to promote wellbeing during social distancing. As the world transitions to the second phase of the pandemic and lockdown restrictions 
gradually lift, balancing autonomy with public health is a challenge. Most patients desire greater shared decision-making [22], thus supportive options may yield better adherence than strict directives. We have compiled easily-accessible resources to support physical activity, mental engagement, and emotional wellbeing (Fig. 2) [23, 24].

Allied health services have been disrupted internationally [25]. COVID-19 has resulted in rapid transitions to telehealth for both physicians and allied health professionals, amplifying a pre-pandemic, recognized need for tele-rehabilitation [26]. Prior work has demonstrated the feasibility and benefits of various tele-rehabilitation models for PD, including supervised exercise via video-conference, virtualreality based therapy, fall prevention therapy via telemedicine, and video-based group classes [27-29], as well as interventions specific to other neurologic conditions [30-32]. While the COVID-19 rehabilitation literature is evolving [33, 34], we are unaware of any published descriptions of tele-rehabilitation for parkinsonian patients during the pandemic. The availability of virtual rehabilitation may vary and neurologists should assess local availability of such services, using the informal online programs in Fig. 2 to bridge gaps in the interim.

Depression, anxiety, and apathy are critical nonmotor symptoms of PD and parkinsonism [8, 10], which may be especially important as pandemicrelated psychological impact has been reported [35]. Supporting cognitive engagement and emotional wellbeing is helpful, and participation in group activities mitigates stressors, thus we list at-home/virtual opportunities and online support groups [36, 37]. Neurologists can also preemptively offer stress and crisis support service resources (Fig. 2).

The pandemic-driven rise in the use and scale of telehealth warrants consideration of challenges particular to this patient population [38, 39]. Practical telehealth tips include reminders to charge devices, silence notifications, gather questions and medication lists, and utilize necessary hearing aids or voice amplifiers. If home equipment is available, vital signs and weight can be measured pre-visit. The patient should sit before the camera with a simple background, with space to move, and near a router. We recommend clarifying that calls from the healthcare team may come from a blocked or 800 number. By emphasizing an after-visit summary will be available via the telehealth platform or mail, we alleviate caregivers' scramble to adjust devices, ask questions, and transcribe recommendations.
For older parkinsonian patients with sensory impairments, dementia, paranoia, hallucinations, and/or delusions, telehealth can be challenging. We recommend healthcare professionals: reintroduce themselves, even to longstanding patients; normalize concerns or paranoia about technology; facilitate some one-on-one patient interaction in which caregivers step away briefly, and vice versa, when possible. Some patients suffering from exacerbated hallucinations, delusions, or elder abuse during this crisis may not disclose this otherwise. Importantly, the telehealth-mediated gait assessment presents an opportunity for a quick home safety assessment: the patient can walk through their home, followed by a caregiver bearing the camera, allowing for observation of fall hazards and provision of safety recommendations.

\section{CONCLUSION}

The COVID-19 pandemic introduced a new reality, presenting opportunities and challenges. Screening and support during this unprecedented time can be proactively offered, as described in this outreach program. Based on feedback from patients and families, and uptake of components among other clinicians, we contend that a proactive outreach program may be valuable, timely, and adaptable to other centers. Online resources can support wellbeing and telehealth strategies for this group may be useful as we encourage our most vulnerable patients to continue social distancing. Amid a barrage of mixed messages and decontextualized data, let us not underestimate the value of clear, personalized, actionable recommendations from trusted clinicians.

\section{ACKNOWLEDGMENTS}

We would like to acknowledge the generous contributions of Ms. Joyce DeMoose, Mr. George Harvey, and an anonymous donor in supporting the COVID outreach program.

B. Sennott, K. Woo, S. Hess, D. Mitchem, E.C. Klostermann reports \& E. Myrick report no disclosures. R. Savica serves on the editorial board of AAN Brain \& Life magazine and receives research support from the National Institute on Aging, the National Institute of Neurological Disorders and Stroke, and the Mayo Clinic Small Grants Program National Center for Advancing Translational Sciences (NCATS) and unrestricted research grant 
from Acadia Pharmaceuticals, Inc. J.E. Fleisher is supported by K23NS097615 and serves as a consultant for UCB Biosciences, Inc., serves on the editorial board of AAN Brain \& Life magazine, receives royalties from UpToDate, receives research support from NIH/NINDS, PCORI, Biogen, Parkinson's Foundation, and has received research support from NIH/NINDS, CurePSP, American Neurological Association, Feldstein Medical Foundation, and the Doris Duke Charitable Foundation Fund to Retain Clinical Scientists.

\section{CONFLICT OF INTEREST}

The authors have no conflict of interest to report.

\section{REFERENCES}

[1] World Health Organization. Coronavirus disease (COVID19) Pandemic. Accessed, June 29, 2020. https://www. who.int/emergencies/diseases/novelcoronavirus-2019

[2] Papa SM, Brundin P, Fung VSC, Kang UJ, Burn DJ, Colosimo C, Chiang H-L, Alcalay RN, Trenkwalder C (2002) Impact of the COVID-19 pandemic on Parkinson's disease and movement disorders. Mov Disord 35, 711-715.

[3] Helmich RC, Bloem BR (2020) The impact of the COVID19 pandemic on Parkinson's disease: Hidden sorrows and emerging opportunities. J Parkinsons Dis 10, 351-354.

[4] Mao L, Jin H, Wang M, Hu Y, Chen S, He Q, Chang J, Hong C, Zhou Y, Wang D, Miao X, Li Y, Hu B (2020) Neurologic manifestations of hospitalized patients with coronavirus disease 2019 in Wuhan, China. JAMA Neurol 77, 1-9.

[5] Helms J, Kremer S, Merdji H, Clere-Jehl R, Schenck M, Kummerlen C, Collange O, Boulay C, Fafi-Kremer S, Ohana M, Anheim M, Meziani F (2020) Neurologic features in severe SARS-CoV-2 infection. N Engl J Med 382, 2268-2270.

[6] Antonini, A, Leta, V, Teo, J, Chaudhuri KR (2020) Outcome of Parkinson's disease patients affected by COVID-19. Mov Disord 35, 905-908.

[7] Shalash A, Roushdy T, Essam M, Fathy M, Dawood NL, Abushady EM, Elrassas H, Helmi A, Hamid E (2020) Mental health, physical activity, and quality of life in Parkinson's disease during COVID-19 pandemic. Mov Disord, doi: $10.1002 / \mathrm{mds} .28134$.

[8] Leibson CL, Maraganore DM, Bower JH, Ransom JE, O'brien PC, Rocca WA (2006) Comorbid conditions associated with Parkinson's disease: A population-based study. Mov Disord Soc 21, 446-455.

[9] Santos García D, Suárez Castro E, Expósito I, de Deus T, Tuñas C, Aneiros A, López Fernández M, Núñez Arias D, Bermúdez Torres M (2017) Comorbid conditions associated with Parkinson's disease: A longitudinal and comparative study with Alzheimer disease and control subjects. J Neurol Sci 373, 210-215.

[10] McLean G, Hindle JV, Guthrie B, Mercer SW (2017) Co-morbidity and polypharmacy in Parkinson's disease: Insights from a large Scottish primary care database. $B M C$ Neurol 17, 1-8.
[11] Fleisher JE, Sweeney MM, Oyler S, Meisel T, Friede N, Di Rocco A, Chodosh J (2019) Disease severity and quality of life in homebound people with advanced Parkinson disease. Neurol Clin Pract. doi: 10.1212/CPJ.0000000000000716.

[12] Nwabuobi L, Barbosa W, Sweeney M, Oyler S, Meisel T, Di Rocco A, Chodosh J, Fleisher JE (2019) Sex-related differences in homebound advanced Parkinson's disease patients. Clin Interv Aging 14, 1371-1377.

[13] Fleisher JE, Klostermann EC, Hess SP, Lee J, Myrick E, Chodosh J (2020) Interdisciplinary palliative care for people with advanced Parkinson's disease: A view from the home. Ann Palliat Med 9(Suppl 1), S80-S89.

[14] Pub 100-02 Medicare Benefit Policy: Clarification of the Confined to the Home Definition in Chapter 15, Covered Medical and Other Health Services of the Medicare Benefit Manual; 2014. Accessed August 15, 2015. https://www.cms.gov/Regulations-and0Guidance/ Guidance/Transmittals/downloads/R192BP.pdf

[15] Ornstein KA, Leff B, Covinsky KE, Ritchie CS, Federman AD, Roberts L, Kelley AS, Siu AL, Szanton SL (2015) Epidemiology of the homebound population in the United States. JAMA Intern Med 175, 1180-1186.

[16] Zeltzer BB, Kohn R (2006) Mental health services for homebound elders from home health nursing agencies and home care agencies. Psychiatr Serv 57, 567-569.

[17] Klietz M, Tulke A, Müschen LH, Paracka L, Schrader C, Dressler DW, Wegner F (2018) Impaired quality of life and need for palliative care in a German cohort of advanced Parkinson's disease patients. Front Neurol 9, 120.

[18] Hassan A, Wu SS, Schmidt P, Dai Y, Simuni T, Giladi N, Bloem BR, Malaty IA, Okun MS, NPF-QII Investigators (2013) High rates and the risk factors for emergency room visits and hospitalization in Parkinson's disease. Parkinsonism Relat Disord 19, 949-54.

[19] Mantri S, Fullard ME, Beck J, Willis AW (2019) State-level prevalence, health service use, and spending vary widely among Medicare beneficiaries with Parkinson disease. NPJ Parkinsons Dis 5, 1.

[20] Spears CC, Besharat A, Monari EH, Martinez-Ramirez D, Almeida L, Armstrong MJ (2019) Causes and outcomes of hospitalization in Lewy body dementia: A retrospective cohort study. Parkinsonism Relat Disord 64, 106-111.

[21] Fleisher JE, Shah K, Fitts W, Dahodwala NA (2016) Associations and Implications of low health literacy in Parkinson's disease. Mov Disord Clin Pract 3, 250-256.

[22] Fotaki M, Roland M, Boyd A, Mcdonald R, Scheaff R, Smith L (2008) What benefits will choice bring to patients? Literature review and assessment of implications. $J$ Health Serv Res Policy 13, 178-184.

[23] Oguh O, Eisenstein A, Kwasny M, Simuni T (2014) Back to the basics: Regular exercise matters in Parkinson's disease: Results from the National Parkinson Foundation QII registry study. Parkinsonism Relat Disord 20, 1221-1225.

[24] Rafferty MR, Schmidt PN, Luo ST, Li K, Marras C, Davis TL, Guttman M, Cubillos F, Simuni T, all NPF-QII Investigators (2017) Regular exercise, quality of life, and mobility in Parkinson's disease: A longitudinal analysis of National Parkinson Foundation Quality Improvement Initiative Data. J Parkinsonism Dis 7, 193-202.

[25] Bettger JP, Thoumi A, Marquevich V, De Groote W, Battistella LR, Imamura M, Ramos VD, Wang N, Dreinhoefer, KE, Mangar A, Ghandi, DB (2020) COVID-19: Maintaining essential rehabilitation services across the care continuum. BMJ Glob Health 5, e002670. 
[26] Ceravolo MG, De Sire A, Andrenelli E, Negrini F, Negrini S (2020) Systematic rapid "living" review on rehabilitation needs due to COVID-19: Update to March 31st 2020. Eur J Phys Rehabil Med. doi: 10.23736/S1973-9087.20.06329-7.

[27] Lai B, Bond K, Kim Y, Barstow B, Jovanov E, Bickel CS (2020) Exploring the uptake and implementation of tele-monitored home-exercise programmes in adults with Parkinson's disease: A mixed-methods pilot study. $J$ Telemed Telecare 26, 53-63.

[28] Giordano A, Bonometti GP, Vanoglio F, Paneroni M, Bernocchi P, Comini L, Giordano A (2016) Feasibility and cost-effectiveness of a multidisciplinary home-telehealth intervention programme to reduce falls among elderly discharged from hospital: Study protocol for a randomized controlled trial. BMC Geriatr 16, 209.

[29] Gandolfi M, Geroin C, Dimitrova E, Boldrini P, Waldner A, Bonadiman S, Picelli A, Regazzo S, Stirbu E, Primon D, Bosello C, Gravina AR, Peron L, Trevisan M, Garcia AC, Menel A, Bloccari L, Valè N, Saltuari L, Tinazzi M, Smania N (2017) Virtual reality telerehabilitation for postural instability in Parkinson's disease: A multicenter, singleblind, randomized, controlled trial. BioMed Res Int 2017, 7962826.

[30] Seidler KJ, Duncan RP, McNeely ME, Hackney ME, Earhart GM (2017) Feasibility and preliminary efficacy of a telerehabilitation approach to group adapted tango instruction for people with Parkinson disease. $J$ Telemed Telecare 23, 740-746.

[31] Tchero H, Tabue Teguo M, Lannuzel A, Rusch E (2018) Telerehabilitation for stroke survivors: Systematic review and meta-analysis. J Med Internet Res 20, e10867.

[32] Khan F, Amatya B, Kesselring J, Galea M (2015) Telerehabilitation for persons with multiple sclerosis. Cochrane Database Syst Rev 2015, CD010508.
[33] de Sire A, Andrenelli E, Negrini F, Negrini S, Ceravolo MG (2020) Systematic rapid living review on rehabilitation needs due to Covid-19: Update to April 30th 2020. Eur J Phys Rehabil Med. doi: 10.23736/S1973-9087.20.06378-9

[34] Andrenelli E, Negrini F, De Sire A, Arienti C, Patrini M, Negrini S, Ceravolo MG, and the International Multiprofessional Steering Committee of Cochrane Rehabilitation RECOVER action (2020) Systematic rapid living review on rehabilitation needs due to Covid-19: Update to May 31st 2020. Eur J Phys Rehabil Med. doi: 10.23736/S19739087.20.06435-7

[35] Qiu J, Shen B, Zhao M, Wang Z, Xie B, Xu Y (2020) A nationwide survey of psychological distress among Chinese people in the COVID-19 epidemic: Implications and policy recommendations. Gen Psychiatr 33, e100213.

[36] Prado L, Hadley R, Rose D (2020) Taking time: A mixed methods study of Parkinson's disease caregiver participation in activities in relation to their wellbeing. Parkinsons Dis 2020, e7370810.

[37] Shah SP, Glenn, GL, Hummel, EM, Hamilton, JM, Martine, RR, Duda, JE, \& Wilkinson JR (2015) Caregiver tele-support group for Parkinson's disease: A pilot study. Geriatr Nurs 36, 207-211.

[38] Wosik J, Fudim M, Cameron B, Gellad ZF, Cho A, Phinney D, Curtis S, Roman M, Poon EG, Ferranti J, Katz JN, Tcheng J (2020) Telehealth transformation: COVID-19 and the rise of virtual care. J Am Med Inform Assoc 27, 957-962.

[39] Smith AC, Thomas E, Snoswell CL, Haydon H, Mehrotra A, Clemensen J, Caffery LJ (2020) Telehealth for global emergencies: Implications for coronavirus disease 2019 (COVID-19). J Telemed Telecare 26, 309-313. 